
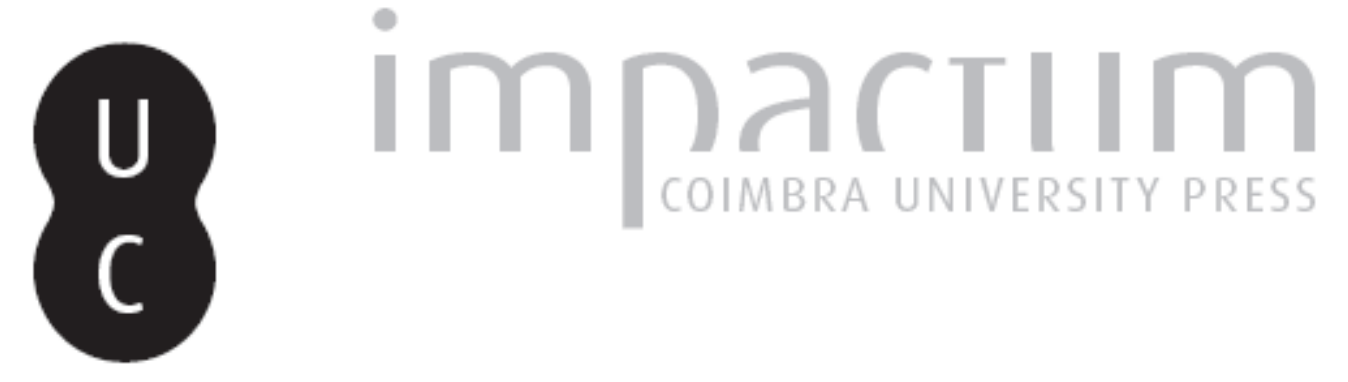

\title{
Entre-lugar e lugar-nenhum: Eudoro de Sousa, de Portugal à Brasília
}

\author{
Autor(es): $\quad$ Guimarães, José Otávio Nogueira
}

Publicado por: Annablume Clássica; Imprensa da Universidade de Coimbra

URL persistente:

URI:http://hdl.handle.net/10316.2/24343

DOI:

DOI:http://dx.doi.org/10.14195/1984-249X_8_7

Accessed : $\quad$ 26-Apr-2023 14:32:23

A navegação consulta e descarregamento dos títulos inseridos nas Bibliotecas Digitais UC Digitalis, UC Pombalina e UC Impactum, pressupõem a aceitação plena e sem reservas dos Termos e Condições de Uso destas Bibliotecas Digitais, disponíveis em https://digitalis.uc.pt/pt-pt/termos.

Conforme exposto nos referidos Termos e Condições de Uso, o descarregamento de títulos de acesso restrito requer uma licença válida de autorização devendo o utilizador aceder ao(s) documento(s) a partir de um endereço de IP da instituição detentora da supramencionada licença.

Ao utilizador é apenas permitido o descarregamento para uso pessoal, pelo que o emprego do(s) título(s) descarregado(s) para outro fim, designadamente comercial, carece de autorização do respetivo autor ou editor da obra.

Na medida em que todas as obras da UC Digitalis se encontram protegidas pelo Código do Direito de Autor e Direitos Conexos e demais legislação aplicável, toda a cópia, parcial ou total, deste documento, nos casos em que é legalmente admitida, deverá conter ou fazer-se acompanhar por este aviso.

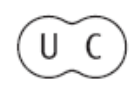


jan.2012

issn $2179-4960$

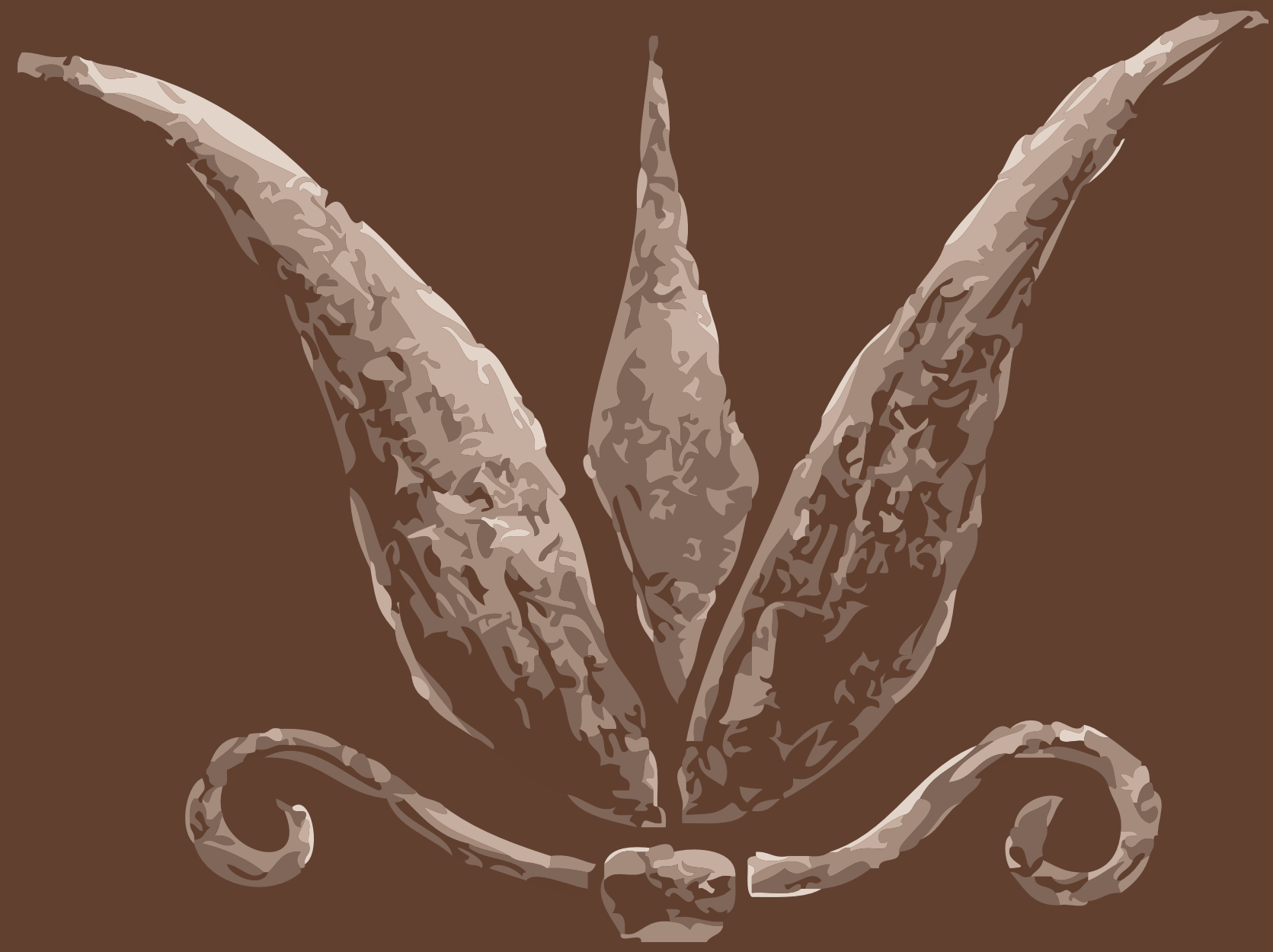

R E V I S T A
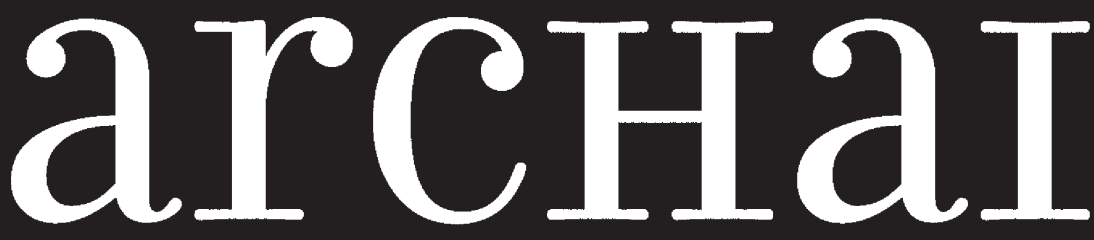

AS ORIGENS DO PENSAMENTO OCIDENTAL

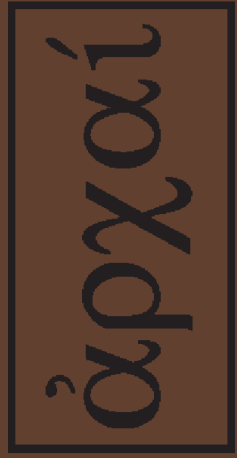

ARCHAI JOURNAL: ON THE ORIGINS OF WESTERN THOUGHT
arcHaI

AS ORIGENS DO PENSAMENTO OCIDENTA.

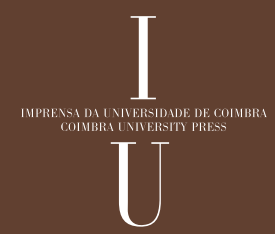

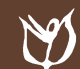




\section{ENTRE-LUGAR E LUGAR-NENHUM: EUDORO DE SOUSA, DE PORTUGAL À BRASÍLIA}

GUIMARÃES, J. 0. N. (2012). “Entre-lugar e lugar-nenhum: Eudoro de Sousa, de Portugal à Brasília". Archai n. 8, jan-jun 2012, pp. 75-79.

RESUMO: Panorama da trajetória intelectual de Eudoro de Sousa (1911-1987), helenista português radicado no Brasil. De seus estudos na Europa ao seu exílio brasileiro, ênfase é conferida à criação do Centro de Estudos Clássicos na Universidade de Brasília em 1962. Que relações de tempo e espaço sua obra entretém com a moderna capital federal brasileira, projetada como um monumento ao novo?

PALAVRAS-CHAVE: Estudos Clássicos, Eudoro de Sousa, Universidade de Brasília.

ABSTRACT: Panorama of the intellectual trajectory of Eudoro de Sousa (1911-1987), Portuguese hellenist radicated in Brazil. From his studies in Europe to his Brazilian exile, emphasis is given to the creation of the Center of Classical Studies in the University of Brasilia, in 1962. What relations os space and time his work maintains with the modern Brazilian capital city, projected as a monument to the New?

KEY-WORDS: Classics, Eudoro de Sousa, University of Brasília.
* Departamento de História - Universidade de Brasília. Brasília. Brasil.
José Otávio Nogueira Guimarães*

Não pretendo, aqui, apresentar a obra, um momento da obra, um livro da obra ou mesmo aspectos da obra do helenista Eudoro de Sousa. Contento-me apenas em evocar sua figura, assinalando lugares de onde veio, por onde passou, deixou de se estabelecer e, finalmente, em exílio, se instalou: lugares geográficos e lugares de fala. Lugares que, como gostava de escrever um historiador de forte dicção filosófica, Michel de Certeau (1975), são simultaneamente inscrições no tempo e no espaço.

0 tema articulador do V Seminário Archai, a cidade antiga, não é, obviamente, estranho à ideia de lugar. Realizado em Brasília, porto final do apolis Eudoro, o Seminário convida a refletir sobre a presença da Antiguidade europeia nesse espaço urbano e nessa universidade pensados e concretizados sob o signo do novo. Foi na Universidade de Brasília que, em 1962, Eudoro de Sousa criou o Centro de Estudos Clássicos (CEC), curta, mas extremamente produtiva, experiência de pesquisa e ensino de pós-graduação, acompanhada da montagem de um expressivo acervo bibliográfico dedicado a esse campo de estudos. Um cronista do mundo acadêmico brasileiro, dotado de imaginação, poderia ter registrado que uma nau antiga, após acostar em vários portos mediterrâneos, abastecer-se em Portugal (esse rosto com o qual 
a Europa fita o Atlântico), ${ }^{1}$ cruzar as colunas de Hércules, veio ancorar às margens do inventado, porque artificial, Lago Paranoá. Não é de todo sem propósito lembrar que foi sob o título de um “marinheiro vagabundo" que Agostinho SILVA (1987, p. 31), agente da vinda do helenista português para Brasília, traçou o contorno da figura de Eudoro de Sousa em um artigo publicado em 1987.

Em que ordem do tempo, contudo, teria se dado essa viagem? Que regime de historicidade poderia dar conta da presença dos antigos, em particular dos gregos de Eudoro, no moderno de Oscar Niemeyer, Lúcio Costa, Darcy Ribeiro e Anísio Teixeira?

\section{II}

Começo por recordar que nas Antilhas, onde se diz que pela primeira vez um europeu tocou 0 Novo Mundo, em Cuba mais precisamente, quando um nativo insular quer expressar o teor de antiguidade de alguma coisa não encontra termo melhor de comparação que a fortaleza do "Morro", guarda da baía de Havana, cuja construção terminou em meados do século XVII. Um dito popular cubano diz: "más viejo que el Morro" (CANCELA, 1995, p. 5). A expressão, entre muitas outras, é significativa de como é relativo o "antigo" em nossas terras americanas. 0 que são esses aproximadamente 400 anos de idade do "antigo" cubano se comparados aos milênios do substrato cultural pré-helênico ao qual foram consagrados tantos textos de Eudoro de Sousa? Para não se falar desses milênios de história antiga europeia comparados aos juvenis 50 anos da capital federal brasileira. Aqui, o antigo, dizem os autóctones (perdoem-me os "estrangeiros" o caráter local da anedota), é o Beirute. Ainda ontem, o velho bar e restaurante de Brasília comemorava, orgulhoso de sua tradição, seus 40 anos. A despeito, porém, de sua juventude e de sua modernidade, Brasília, desde 1987, tornou-se, sob a autoridade da UNESCO, patrimônio cultural da humanidade. Recém fundada e já tombada. Trata-se de um moderno que envelheceu rápido, marcado precocemente pelas rugas de um tempo cada vez mais acelerado? 0u trata-se, antes, do moderno que já se quer aureolado com o prestígio do antigo, preocupado em garantir, paradoxalmente e de antemão, o status de clássico, de forma a se proteger da corrosão desse tempo que tudo altera, senhor do esquecimento? Sob o signo de um antigo relativizado e de uma crise do regime moderno de historicidade, evoquemos, então, alguns lugares de Eudoro de Sousa. ${ }^{2}$

\section{III}

Ele nasceu na capital portuguesa, em 27 de dezembro de 1911. Iniciou seus estudos superiores na Faculdade de Ciências da Universidade de Lisboa, sem nunca tê-los concluído. Surpreende ler a nota de agradecimento que o português José Garcia Domingues escreveu, em 1939, em sua tese de docência universitária (Da essência, da existência e da valência): “devo ao meu amigo Eudoro de Sousa uma valiosa iniciação científica, principalmente nos domínios da matemática (teoria dos números, teoria das funções, cálculo diferencial, integral, vetorial, tensorial, das probabilidades, geometrias não-euclidianas etc)" (apud Domingues, 2003, p. 78). Desse Eudoro "cientista" sobreviveria, sob o céu de Brasília, o astrônomo amador. Ele chegou a idealizar, na Universidade de Brasília, o projeto de um observatório que, após ser aprovado por equipe do Departamento de Física da Universidade de São Paulo, nunca pode, infelizmente, tomar forma.

Eudoro deixaria uma primeira vez Lisboa, em meados da década de 1930, para estudar em Paris. Frequentou aí cursos de teologia e filosofia no Seminário Maior de Saint-Sulpice e de história e filosofia no Institut Catholique; acompanhou também vários seminários no Collège de France. Conta Agostinho Silva que Eudoro estudava, nessa época, para ser secretário do cardeal-patriarca de Lisboa. A opção religiosa, com ambições episcopais, seria abandonada algum tempo depois. 0 cristianismo e mais amplamente certa experiência do sagrado deixariam, contudo, marcas sensíveis na interpretação eudoriana da cultura helênica. Elas são visíveis, por exemplo, na ideia da Grécia como um entre-lugar. Entre-lugar é o termo usado por Jacyntho Lins Brandão, na precisa resenha crítica que escreveu de Dioniso em Creta (1973), em que mostra que a mito-religião grega (objeto principal desse livro de Eudoro), tal como pensada em uma temporalidade tripartite, apenas se dá a entender "considerando-
1. “A Europa jaz, posta nos cotovelos: / De Oriente a Occidente jaz, fitando, / E toldamthe românticos cabelos / Olhos gregos, lembrando. / [...] Fita, com olhar sphyngico e fatal, / 0 Occidente, futuro do passado. / 0 rosto com que fita é Portugal". Fernando PESSOA, "Mensagem", em 0 eu profundo e os outros eus (seleção poética), $10^{\mathrm{a}}$ ed., Rio de Janeiro: Nova Fronteira, 1980: 45.

2. Acerca da noção de regime de historicidade e da crise do regime moderno, ver Hartog (2003). 
-se aquilo donde ela provém (o mito pré-helênico)" e "aquilo em que desemboca (a revelação cristã)" (BRANDÃ0, 2003, p. 87).

Depois de Paris, o destino de Eudoro é a Alemanha, onde se especializou em filologia clássica e história antiga na Universidade de Heidelberg. A estadia teuta redundou não só em iniciação nos sérios métodos da Ciência da Antiguidade (Altertumswissenschaft), como também em reforço de uma atitude espiritual que via a Grécia fortemente enraizada na tradição do romantismo alemão. Tal atitude voltaria a se manifestar pela presença heideggeriana nos últimos trabalhos do helenista.

De volta à Lisboa, Eudoro reintegrou-se ao movimento da "filosofia portuguesa", recebendo aí, por intermédio de Álvaro Ribeiro e José Marinho uma paideia filosófico-literária que, em sua vida intelectual, manter-se-ia sempre em tensão com sua formação franco-alemã de historiador, filólogo e filósofo. Eudoro guardaria essa dupla orientação, ou melhor, para utilizar um termo que sempre the foi caro, essa complementaridade na sua maneira de abordar a Grécia. Complementaridade consubstanciada em seus primeiros artigos publicados, ainda em Portugal, sobre Novalis e Pessoa. De um lado, assim, um dos mais representativos poetas românticos, para quem a poesia, longe de reduzir-se a um exercício estético, é a expressão, ou mesmo a via, de uma experiência espiritual mais ampla. É digno de nota que as primeiras aulas que Eudoro ministrou na Universidade de Brasília, sob o formato de um curso de extensão, versaram sobre (era o título do curso) “A Antiguidade clássica e o pensamento romântico" (Menezes, 2002: 23). De outro lado, a dicção metafísica da literatura lusa. Eudoro costumava dizer que o "filósofo" que mais o tinha influenciado havia sido Fernando Pessoa (BASTOS, 1986: 112). Ao se envolver, em 1943, em um debate sobre a capacidade especulativa dos portugueses, Eudoro não se alinhara com os que entendiam a ausência de uma filosofia local como sinal de inferioridade. Portugal, segundo ele, tinha em contrapartida uma tradição riquíssima e própria para exprimir “a verdade que é a nossa verdade, aquela que nos acordes da lira poética é como verdade sonhada, e que, na simpática vibração da alma popular, é como verdade esquecida" (SOUSA, 2000, p. 277).
Esse tipo de formulação não é estranho, muito pelo contrário, ao movimento cultural luso do primeiro terço do século XX, chamado Renascença Portuguesa, fundado por José Leonardo Coimbra (1883-1936), que reconhecia a necessidade de recompor a unidade do saber disperso das "mais altas disciplinas espirituais", como a metafísica, a religião e a poesia. Os primeiros escritos de Eudoro são profundamente marcados por esse ambiente. A tertúlia filosófica lisboeta que frequentara - com Jorge de Sena e Almado Negreiros, por exemplo - afastava-se da ideia de um valor puramente estético conferido à poesia e à literatura. A religião, a filosofia e a poesia deviam convergir no absoluto. As palavras de José Marinho sobre Eudoro, em Verdade, condição e destino do pensamento português, de 1973, insiste nessa tecla: "alguns [dos seus] estudos, nos quais se concilia a exigência de rigor com agudo sentido da imagética primordial e da simbólica, [...] têm afinidade funda com a poética portuguesa e a situação das nossas mais difíceis formas de filosofia" (MARINH0, 1976, p. 62).

\section{IV}

0 problema é que Eudoro não encontraria em Portugal uma inserção profissional à altura de seus investimentos intelectuais. Um emprego burocrático o torna sensivel à segregação institucional a que se viu sujeito. Resta-lhe o exílio voluntário. A ideia se the apresenta ao se candidatar a uma bolsa de estudos no Brasil. Do outro lado do Atlântico, contudo, ao invés de o aceitarem como aluno, nomearam-no professor. Eudoro chega a São Paulo, em 1953, aos 42 anos de idade. Integra-se ao chamado "Grupo de São Paulo", intelectuais que se reúnem em torno da revista Diálogos e do Instituto Brasileiro de Filosofia. Desenvolve atividades acadêmicas na Universidade de São Paulo, na Faculdade de Filosofia de Campinas e na Pontifícia Universidade Católica (SP). Um amigo português, Orlando Vitorino, conta que Eudoro, ao deixar Portugal, jurou nunca mais voltar e jamais mandar notícias (VITORINO, 1987). Cumprindo o juramento e tentando deixar de atender à presença do substrato português em seu pensamento e erudição, passou a escamotear a referência intelectual lusa e dar valor e destaque à especulação alemã. Data 
desse momento sua ativa participação no grupo de heideggerianos paulistas, comandados por Vicente Ferreira da Silva, do recém citado Instituto Brasileiro de Filosofia.

Há quem diga, no entanto, que foi inspirado pelas reflexões de Leonardo Coimbra (o fundador da Renascença Portuguesa) sobre a 'coisificação' que Eudoro se lançou na tradução do lúdico ensaio de Heidegger, "A coisa" (Das Ding). Não há nenhuma dúvida de que a efusiva discursividade de Heidegger seduziu o filólogo Eudoro. Teodoro Assunção, em resenha crítica nada encomiástica de Mitologia 1: mistério e surgimento do mundo (livro no qual Eudoro publicou como apêndice justamente sua tradução de "A coisa", de Heidegger) já havia notado o "fascínio e reverência" de Eudoro por um "certo saber 'originário'", que teria levado o português a "mimetizar o estilo do mestre" alemão. Assunção vai mais longe ao falar que temas de Heidegger modelam o pensamento de Eudoro. Em suma, o estilo livre, sobretudo do segundo Heidegger, teriam marcado "negativamente" (o termo é de Assunção) a escrita de Eudoro, "caracterizada também por um culto neorromântico ao 'poético'" (ASSUNÇÃO, 2003, p. 97).

Dois anos em São Paulo (1953-1955) e Eudoro parte para Santa Catarina, onde permanece por 7 anos. Em 1962, por indicação de Agostinho Silva, que já o havia levado para a ilha de Florianópolis, mas que, desde 1960, colaborava com Darcy Ribeiro na criação da nova universidade da capital federal, Eudoro de Sousa é convidado a fazer parte da recém criada Fundação Universidade de Brasília. Já em seu primeiro ano de Planalto Central, 1962, Eudoro idealiza, cria e começa a conduzir o Centro de Estudos Clássicos (CEC). Em apenas 7 anos, consegue montar uma impressionante biblioteca, um dois mais expressivos acervos, pelo menos até finais dos anos 1970 e em âmbito latino-americano, relativo ao estudo do mundo antigo ocidental. Passam a funcionar ali um mestrado e um doutorado em Estudos Clássicos: dissertações e teses são defendidas. Uma geração de helenistas e latinistas brasileiros é formada na moderna Brasília dos anos 1960: sem ser exaustivo, lembro dos nomes de Jair Gramacho, José Xavier de Mello Carneiro, João Ferreira, João Evangelista,
Fernando Bastos, Dinah Fernandes Brognoli, Emanuel Araújo, Ordep José Trindade Serra, Antonio Telmo Carvalho Vitorion e Suetônio Valença. 0 Centro se extingue em 1969, por conta de reforma universitária conduzida pelo regime militar, que passou a impedir o funcionamento das chamadas unidades complementares, tornando o departamento a célula principal da vida acadêmica. 0 grupo de classicistas se dispersará, não só pelas unidades departamentais no interior da Universidade de Brasília, mas, em seguida, por todo o país.

É sem lugar, portanto, que Eudoro começa a encarar os anos 1970. Já geograficamente exilado, ele é despejado da pequena pátria Antiga que construíra no seio da moderna Brasília, seu Centro de Estudos Clássicos. Pingando de departamento em departamento, Eudoro resistiria até o dia que em foi escalado para ministrar a disciplina Grego I para principiantes. Um colega, reparando em seu aspecto um tanto deprimido, procurou o então reitor para argumentar que era um desperdício manter um intelectual da estatura de Eudoro, que tanto tinha feito pela Universidade de Brasília, ensinando o bê-á-bá do grego. Não seria melhor deixá-lo colocar por escrito suas importantes reflexões filosóficas? 0 reitor concordou. Dispensado nesse momento de carga docente, tratado quase como um fellow de 0xford, Eudoro começou a produzir o grosso de sua obra: Dionísio em Creta, Horizonte e complementaridade, Mitologias I e II, além de suas famosas traduções (anotadas e comentadas) da Poética de Aristóteles e de As Bacantes de Eurípedes.

Essa obra sobre um entre-lugar, a Grécia, feita de lugar-nenhum, a Brasília dos anos 1970, é assunto para os artigos que se seguem. Apenas uma última questão. Esse lugar-nenhum e a sensação de relatividade temporal, a que nos referimos no início desse texto, não ressoa na própria maneira como Eudoro construiu sua relação intelectual com o mundo grego antigo? No texto que encerra Mitologia II, "A Grécia e a história", pode-se ler: "dentro de uma época, a atualidade que a individualiza e caracteriza, atrai a si, por força retroativa, a sua própria antiguidade. (...) Qualquer atualidade tem sua própria antiguidade; diríamos até, que tem a antiguidade que merece" (SOUSA, 1988, p. 84). 


\section{REFERÊNCIA BIBLIOGRÁFICA}

ASSUNÇÃO, Teodoro Rennó (2003). “Jargão filosófico e jogo da vida", Humanidades n. 50, p. 96-100.

BASTOS, Fernando (1986). “Eudoro de Sousa e a complementaridade", Humanidades n. 11.

BRANDÃ0, Jacyntho Lins (2003). “Dioniso e a diacosmese da cultura helênica", Humanidades n. 50, p. 84-87.

CANCELA, Elina Miranda (1995). “La tradición clásica e Cuba", Sociedade Brasileira de Estudos Clássicos, Sociedad Chilena de Estudios Clásicos, Asociación Argentina de Estudios Clásicos. [Brochura]

CERTEAU, Michel de (1975). L'écriture de l'histoire. Paris, Gallimard.

DOMINGUES, Joaquim (2003). "0 culto e a cultura”, Humanidades n. 50, p. 78-83.
HARTOG, François (2003). Régimes d'historicité: présentisme et expériences du temps. Paris, Le Seuil.

MARINHO, José (1976). Verdade, Condição e Destino do Pensamento Português. Porto, Lello \& Irmão.

MENEZRS, Thiago Castro Dória de (2002). 0 Centro de Estudos Clássicos e a Universidade de Brasília: uma história, monografia de conclusão de curso (sob a orientação de Sonia Lacerda), Departamento de História, UnB.

SILVA, Agostinho (1987). "Um marinheiro vagabundo". Lisboa, Jornal de Letras, 3 de outubro de 1987, p. 31.

SOUSA, Eudoro de (1988). "História e Mito" - Mitologia 2. Brasília, Editora Universidade de Brasília.

(2000). Origem da poesia e da mitologia e outros ensaios dispersos. Lisboa: Imprensa Nacional/Casa da Moeda.

VITORINO, Orlando (1987). “Duas figuras literárias desparecidas", Letras em trânsito, p. 196.

Recebido em novembro de 2011. Aprovado em dezembro de 2011. 